\title{
HYDROLOGICAL HAZARDS ASSESSMENT AND MANAGEMENT IN SLOVAKIA
}

\author{
Martina ZELEŇÁKOVA ${ }^{1}$, Maria Manuela PORTELA ${ }^{2}$, P. PURCZ ${ }^{3}$, P. \\ BLIŠT $\check{T} N^{4}$, Helena HLAVATA ${ }^{5}$
}

\begin{abstract}
Hydrological hazards assessment and management in Slovakia. One of the purpose of Water Framework Directive (WFD) (2000/60/EC) is to contribute to mitigating the effects of floods and droughts - hydrological hazards occurring nowdays more often in river basins. Effective water management, as required by the WFD, helps Member States prepare for extreme weather events which, due to climate change, are becoming more frequent and cause tremendous damages. The study of climatological data is performed with goal to reduce impacts of droughts and floods and thus to ensure sustainable and proper water resources management. Based on the precipitation time series obtained from Slovak Hydrometeorological Institute at a number of climatic stations over a considerable span of time a comprehensive analysis for the entire Slovakia is being carried out. Some of methods applied as well as some of the results achieved are briefly mentioned in this paper, namely (i) trend analysis applied to precipitation time series, (ii) the temporal and spatial evolution of climatological hazards in the area, and (iii) proposal of hazard mitigation measures. It is found increasing trends in precipitation time series in the most of stations in Slovakia, although it is also proved that the droughts are recurrent in Slovakia. The paper identifies climatological extremity in the country that significantly influences water resources management. It presents actual measures for proper water management in river basins aimed to mitigation of hydrological risks.
\end{abstract}

Keywords: causative factors, floods, geographical information system, multicriteria analysis.

\section{INTRODUCTION}

Directive 2007/60/EC on the assessment and management of flood risks entered into force on 26 November 2007. This Directive now requires Member

1 Technical University of Kosice, Faculty of Civil Engineering, Vysokoškolská 4, 04200 Kosice, Slovakia, e-mail: martina.zelenakova@tuke.sk

2 Technical University of Lisbon, Av. Rovisco Pais 1, 1049-001 Lisbon, Portugal, e-mail: maria.manuela.portela@ist.utl.pt

3 Technical University of Kosice, Faculty of Civil Engineering, Vysokoškolská 4, 04200 Kosice, Slovakia, e-mail: pavol.purcz@tuke.sk

4 Technical University of Kosice, Faculty of Mining, Ecology, Process Control and Geotechnology, Park Komenského 19, 04200 Kosice, Slovakia, e-mail: peter.blistan@tuke.sk

5 Slovak Hydrometeorological Institute Kosice, Dumbierska 26, 04117 Kosice, Slovakia, e-mail: helena.hlavata@shmu.sk 
States to assess if all water courses and coast lines are at risk from flooding, to map the flood extent and assets humans at risk in these areas and to take adequate and coordinated measures to reduce this flood risk. While Europe is by large considered as having adequate water resources, water scarcity and drought is an increasingly frequent and widespread phenomenon in the European Union. The major challenge from water scarcity and droughts has been recognized in the Communication "Addressing the challenge of water scarcity and droughts" from the European Commission adopted in 2007 (COM, 2007).

When extreme and non-extreme physical events, such as floods and droughts can affect elements of human systems in an adverse manner, they assume the characteristic of a hazard (Lavell et al., 2012). Generally speaking, hazard is understood as the potential damage or damage created by an event, a natural disaster, an occurrence, phenomenon or human activity which can cause a loss of lives, injury, damage to property, an interruption of social or economic networks and activities, or environmental degradation (IPCC, 2012). Hazard is a threat or potential for adverse effects, not the physical event itself (Lavell et al., 2012). The greater the hazard, the longer the exposure and the greater the vulnerability of an object, the greater is the risk (Langhammer and Vilímek, 2008).

The aim of this contribution is assessment and management of the impacts of regional climate in Slovakia based on precipitation trend analysis and Standard precipitation indexes evaluation.

\section{MATERIAL AND METHODS}

The territory of Slovakia belongs to Danube river basin (Fig. 1). Slovakia is in the light of global climate classification situated in the northern temperate climatic zone with a regular alternation of four seasons and variable weather, with a relatively even distribution of rainfall throughout the year. In Slovakia, according to the Slovak Hydrometeorological Institute (SHMI), are in average $600 \mathrm{~mm}$ of precipitation per year. Mountains in northwest and north of the country are generally richer in atmospheric precipitation than the lowlands in central, southern and eastern regions of Slovakia. Great variability of precipitation caused mainly in the lowlands frequent and sometimes prolonged periods of drought. In winter, much of the precipitations, particularly in the middle and the high mountain ranges, are in the form of snow. The rainiest month is usually June or July, and the less rainfall is from January to March (SHMI, 2015).

The daily data for trend analysis were obtained from Slovak Hydrometeorological Institute (SHMI) in Košice, Slovakia. The network of rain gauge stations over the Slovak Republic is depicted in Fig. 2. There are 634 rain gauging stations operated by SHMI. For evaluation of trend analysis over whole Slovakia we considered 487 stations for period from 1981 to 2013. In the rest of stations we do not have complete data series. The assessment and management of regional climate in Slovakia was done by using common methods - statistical analysis (trend analysis) and drought indexes. 


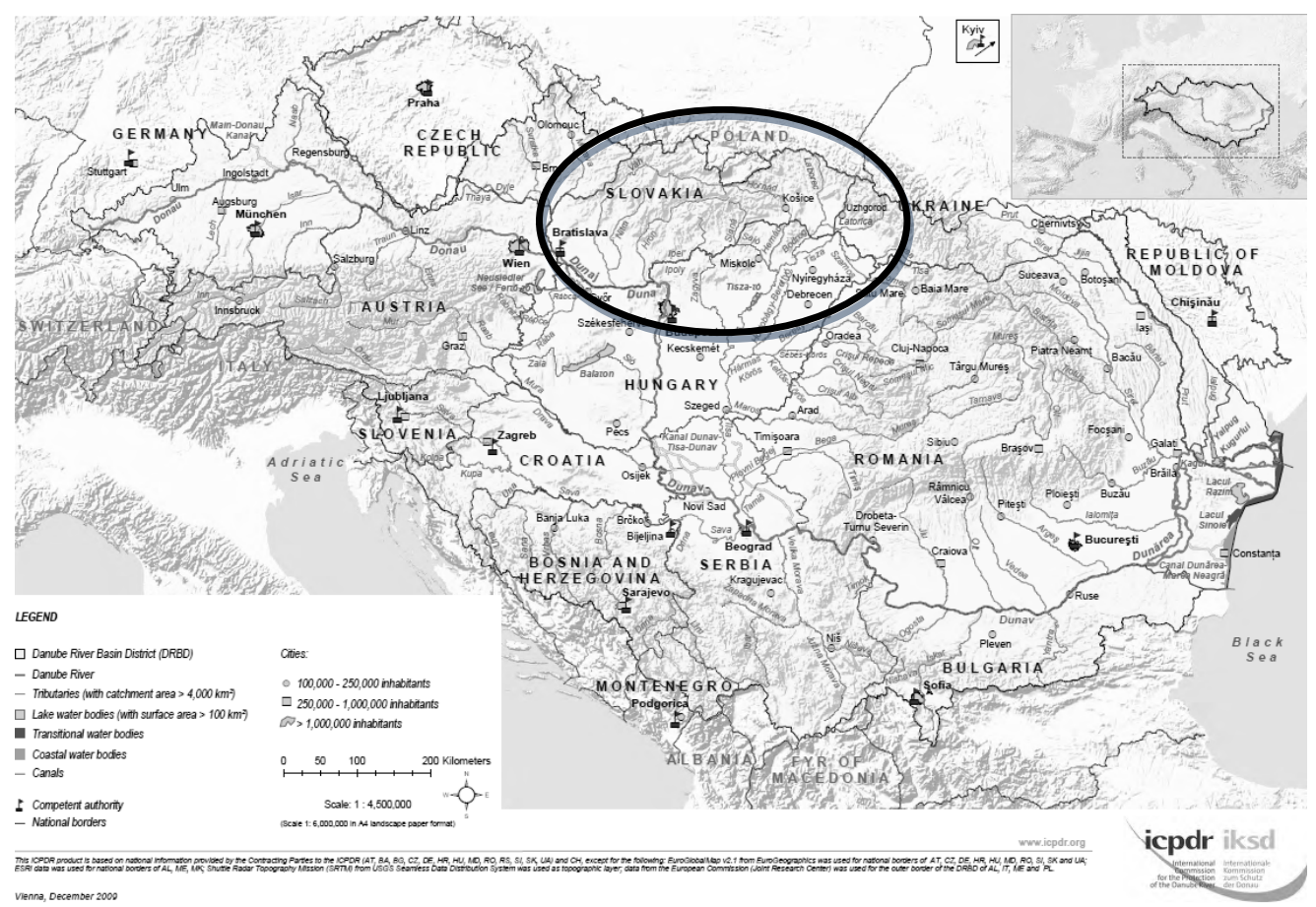

Fig. 1. Slovakia within Danube river basin (source: ICPDR)

Trend analysis for hydrological time series is an important and popular tool for better understanding the effects of climate variation and anthropogenic activities. The Mann-Kendall (MK) test (Kendall, 1975; Mann, 1945) is a rankbased nonparametric test for assessing the significance of a trend, and has been widely used in hydro-meteorological trend detection studies (Lettenmaier et al., 1994; Burn, 2002; Partal and Kahya, 2006; Sayemuzzaman and Jha, 2014 etc.). The magnitude of the trend was determined using Sen`s estimator. Sen's method assumes a linear trend in the time series and has been widely used for determining the magnitude of trend in hydro-meteorological time series (Sen, 1968), etc. We used the mentioned methods for trend detection and its magnitude statement in precipitation time series during the mentioned period.

For the temporal analysis we have used analyzing tools of Microsoft Office Excel 2010 and for the spatial analysis we have used modelling and analyzing tools of ArcGIS 10.3 - Geostatistical Analyst - Kriging and Inverse Distance Weighting.

Drought events were identified based on the SPI3 (McKee et al., 1993) and water scarcity have occurred regularly in Slovakia along the study period (19812013). Country was affected by moderate $(-1.28<$ SPI $3<-0.84)$, severe ($1.65<\mathrm{SPI}<-1.28$ ), and extreme drought (SPI3<-1.65), according to the SPI categories based on the Thiessen polygons (Santos et al, 2010). 


\section{RESULTS}

Analysis of the annual precipitation time-series during the period 19812013 using Mann-Kendall (MK) non-parametric statistical test identified in almost all stations a positive trend (452 of 487 stations or 93\%) and the rest, with a negative trend. The level of significance using Sen estimator value identified 157 stations having significant trend at 95\% confidence level (155 stations with positive trend and 2 stations with negative trend) (Fig. 2). Significant negative trends are found only in north part of the study area, significant positive trends are identified over all the area. In Figure 2 is depicted magnitudes of annual precipitation trends (Sen estimator value) in climatic stations.

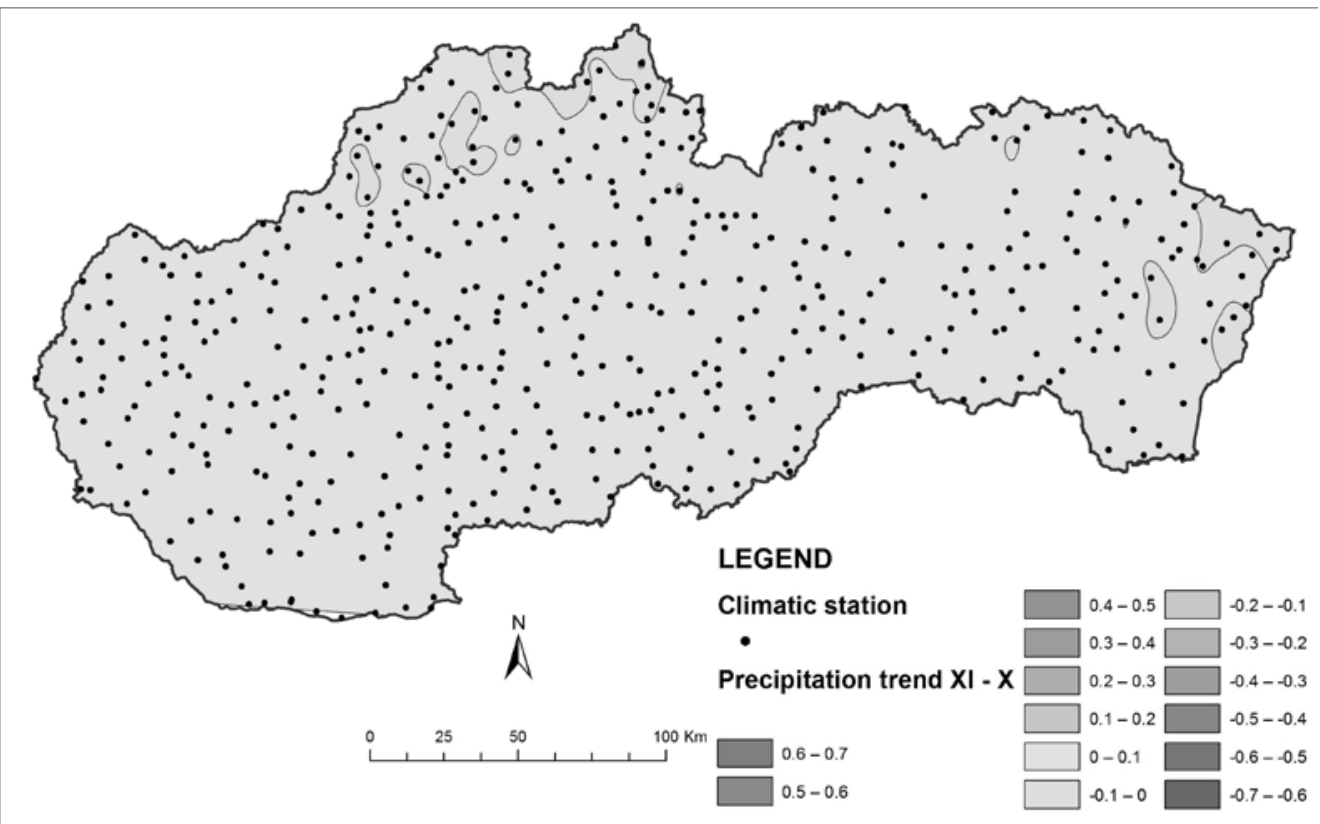

Fig. 2. Annual precipitation trends in Slovakia in 1981-2013 period

Three important drought events, stated based on the SPI3 (Standard Precipitation Index for 3 months), occurred simultaneously in Slovakia - at the beginning of 1982, at the end of 1986 and in April 2011 a generalized extreme drought started with duration of approximately three months - dark columns in plots in Fig. 3 (Portela et al, 2015; Zeleňáková et al, 2015).

Some regions in Slovakia are facing smaller rainfall and longer droughts meaning water scarcity mostly during the summer (central part of the country) while other regions, which are the most often cases, are expected to face increased rainfall and floods (north part of the country).

In the Slovakia, Water Research Institute in cooperation with Slovak Water Management Enterprise, Slovak Hydrometeorological Institute and Ministry of the Environment have identified the localities with probable and existing flood risk 
based on the map at Fig. 4: The annual maximum of 5 days precipitation total with frequency of 0.02 and towns with floods in period 1997-2010, that served as the basis for flood risk mapping.
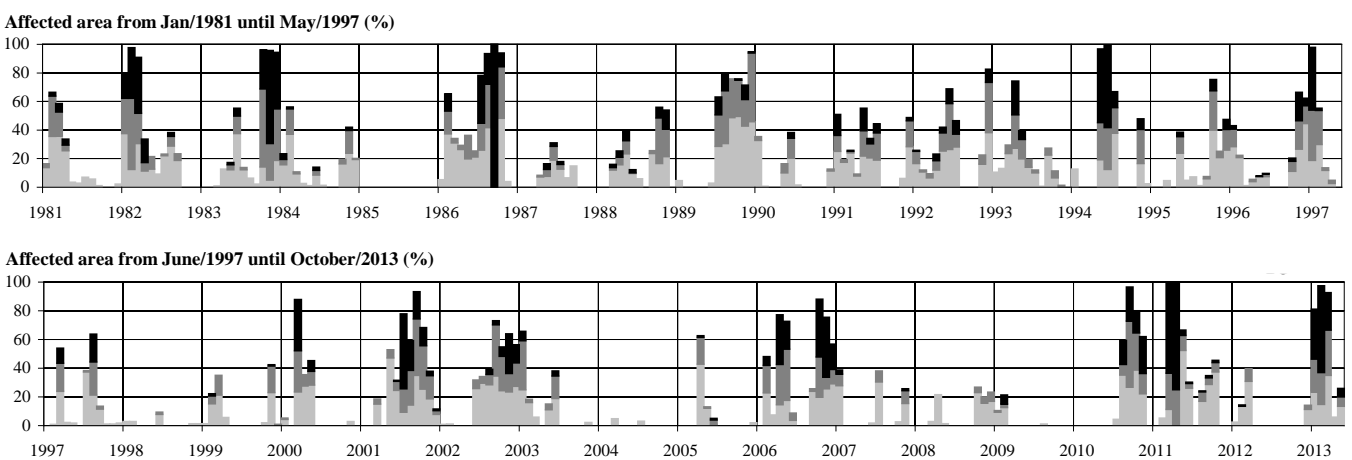

Fig. 3. Drought occurrence based on SPI in Slovakia

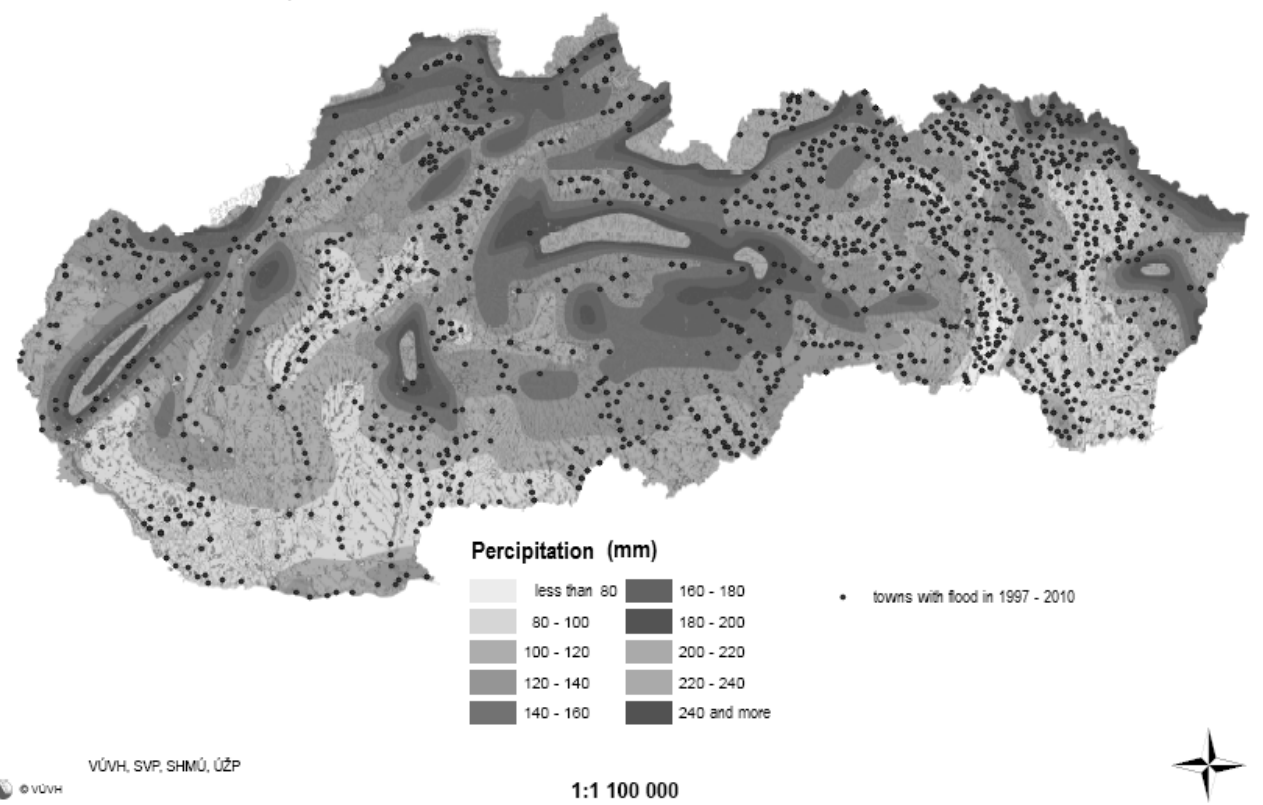

Fig. 4. Map of potential flood risk in Slovak republic (source: SWRI, 2011)

Slovakia established flood risk management plans on the basis of the flood hazard and flood risk maps. Flood risk management plans took into account relevant aspects such as costs and benefits (Rojas et al, 2013), flood extent and flood conveyance routes and areas which have the potential to retain flood water, such as natural floodplains, the environmental objectives of Directive 2000/60/EC, soil and water management, spatial planning, land use, nature conservation, navigation and port infrastructure. The purpose of the flood risk management plans is to identify means of reducing the impacts of flooding. 
A comprehensive hydrological risk management approach consists of a combination of prevention, preparation, response and recovery. The main recommendations for hydrological risk assessment and management (modified according to Simonovic (2009)) are:

- to fully exploit basic and advanced information technologies to improve environmental representation, flood and drought characterization and prediction, and to foster intersectoral communication and collaboration;

- to continue introduction of hydrological risk and impact assessment with any new development proposal;

- to continue advancement of integrated floodplain management principles and practices, including a more fully balanced approach of structural and nonstructural flood protection measures;

- to proceed with the development of variable procedures to more effectively manage the flood and drought risk within various sectors of society;

- to enhance awareness of local flood management capacities and the need for affected groups and individuals to assume their share of the risk;

- to continue advancement of strategies to involve a broader range of groups and individuals in decision-making processes based on common, basin-wide visions; and

- to continue exchange of information related to integrated water resources management through regional and international initiatives and meetings.

Preventive measures reduce the probability of hydrological hazards by spatial planning and construction and maintenance of water works, like water reservoirs (Zeleňáková, 2009). Preparation, response and recovery reduce the consequences when preventive measures fail. Preparation includes emergency planning and early warning. Response includes disaster management, crisis communication and evacuation. Recovery includes rebuilding of damaged assets and payment for financial losses by insurance companies.

\section{CONCLUSIONS}

Despite the relatively high density of rain gauge stations in Slovakia (634), it is almost certain that through this network measurements, only about a third of extremely high short-term events can be recorded ???. ???The cause of flooding is extremely heavy rains or rapid melting of snow combined with a significantly reduced ability to detain stormwater in areas (mainly because of damage of the country - e.g. drained wetlands, farmland, and drainage)???. The primary impulses of torrential floods are usually extremely intense precipitation which falls rapidly in relatively small and sharply defined areas (several $\mathrm{km}^{2}$ ). The total catchment's hydrological response to intense rainfall is determined by its natural environment, a whole complex of characteristics of the river basin. The intensity and frequency of precipitation events, which are capable of extreme runoff and subsequent flooding in Slovakia during recent years has increased significantly. The end of the second 
millennium and the beginning of the third one were characterized in eastern Slovakia by the occurrence of many extreme flood events in a short periods of time, most/all of them followed by devastating consequences . The damage caused by floods is a common effect of two independent mechanisms: natural conditions and the human activities in the basin. Despite of many flood situations, drought events still occurred in the last decades in Slovakia. ???Climatic change is also proved by occurring of these hydrological extremes very often in this area. The floods and drought effects have been observed on all continents and over the last decade the frequency of floods and drought increased mainly as a consequence of climate change.

In general, precipitation data in the study area during the last 33 years have not changed, and there are no big gaps. However, predominantly increasing trends in precipitation time series were found in most of gauging stations in Slovakia although drought events are aslo occurring in the area. The results corroborate previous climatic studies in the area of central Europe, that there is an existing risks of occurrence of extreme hydrological phenomena.

This work has been supported by the Slovak Research and Development Agency project SK-PT-2015-0007 and Scientific Education Agency project 1/0609/14.

\section{REFERENCES}

1. Burn, D.H., Hag Elnur, M.A. (2002), Detection of hydrologic trends and variability. Journal of Hydrology, 255:107-122

2. Kendall, M.G. (1975), Rank Correlation Measures, London: Charles Griffin

3. Langhammer, J., Vilímek, V. (2008), Landscape changes as a factor affecting the course and consequences of extreme floods in the Otava river basin, Czech Republic. Environmental monitoring and assessment, 144:53-66

4. Lavell, A., Oppenheimer, M., Diop, C., Hess, J., Lempert, R., Li, J., Muir-Wood, R., Myeong, S. (2012), Climate change: new dimensions in disaster risk, exposure, vulnerability, and resilience. In: Managing the Risks of Extreme Events and Disasters to Advance Climate Change Adaptation. A Special Report of Working Groups I and II of the Intergovernmental Panel on Climate Change (IPCC). Cambridge University Press, Cambridge, UK, and New York, NY, USA, pp. 25-64

5. Lettenmaier, D.P., Wood, E.F., Wallis, J.R. (1994), Hydro-climato-logical trends in the continental United States, 1948-88. Journal of Climate, 7:586-607

6. Mann, H.B. (1945), Non-parametric tests against trend, Econometrica, 13:245-259

7. McKee, T.B., Doesken, N.J., Kleist, J. (1993), The relationship of drought frequency and duration to time scales. In: Proceedings of the 8th Conference on Applied Climatology, American Meteorology Society, pp. 179-184

8. Partal, T., Kahya, E. (2006), Trend analysis in Turkish precipitation data. Hydrological Processes, 20:2011-2026

9. Portela, M.M., Zelennáková, M., Santos, J.F., Purcz, P., Silva, A.T., Hlavatá, H. (2015), Drought analysis in Slovakia: regionalization, frequency analysis and precipitation thresholds. In: Brebbia CA et al. Eds. 8th International Conference on River Basin Management, La Coruna (Spain), Wessex Institute, New Forest, UK, pp. 3-14 
10. Rojas, R., Feyen, L., Watkiss, P. (2013), Climate change and river floods in the European Union: Socio-economic consequences and the costs and benefits of adaptation. Global Environmental Change, 23:1737-1751

11. Santos, J.F., Pulido-Calvo, I., Portela, M.M. (2010), Spatial and temporal variability of droughts in Portugal. Water Resources Research, 46, doi:10.1029/2009WR008071

12. Sayemuzzaman, M., Jha, M.K. (2014), Seasonal and annual precipitation time series trend analysis in North Carolina, US. Atmospheric Research, 137:183-194

13. Sen, P.K. (1968), Estimates of the regression coefficient based on Kendall's tau. Journal of the American Statistical Association, 63:1379-1389

14. Simonovic, S.P. (2009), Managing flood risk, reliability and vulnerability. J Flood Risk Manage, 2:230-231.

15. Zeleňáková, M., Portela, M.M., Purcz, P., Silva, A.T., Hlavatá, H., Santos, J.F. (2015), Precipitation trend detection for Slovakia, In: Water Resources Management in a Changing World: Challenges and Opportunities. EWRA, Athens, pp. 1-6.

16. Zeleňáková, M. (2009), Flood risk assessment. Košice: Technical University of Košice, Faculty of Civil Engineering.

17. *** (2000) Directive 2000/60/EC of the European Parliament and of the Council of 23 October 2000 establishing a framework for Community action in the field of water policy. Official Journal L 327, 22/12/2000 pp. 0001-0073 (WDF)

18. *** (2007) Directive on the assessment and management of flood risks. Official J, L288, pp. 27-34. Brussels: The European Parliament and the Council of the European Union, (2007/60/EC)

19. *** (2007) Communication from the Commission to the European Parliament and the Council Addressing the challenge of water scarcity and droughts in the European Union, Brussels, 18.7.2007 COM(2007) 414 final

20. *** (2011) Map of potential flood risk in the Slovak Republic. Bratislava: Slovakia Water Research Institute (SWRI).

21. *** (2012) Managing the Risks of Extreme Events and Disasters to Advance Climate Change Adaptation. A Special Report of Working Groups I and II of the Intergovernmental Panel on Climate Change [Field, C.B., V. Barros, T.F. Stocker, D. Qin, D.J. Dokken, K.L. Ebi, M.D. Mastrandrea, K.J. Mach, G.-K. Plattner, S.K. Allen, M. Tignor, and P.M. Midgley (eds.)]. Cambridge University Press, Cambridge, UK, and New York, NY, USA, 582 pp. (IPCC)

22. *** (2015), Climatic conditions of the Slovak Republic, Bratislava: Slovak Hydrometeorologic Institute. Available at: http://www.shmu.sk/sk/?page=1064 (SHMI)

23. *** (2016) Danube river basin. Avaiable at: http://www.icpdr.org/icpdrpages/drbmp_maps_2009.htm (ICPDR) 